http://jmscr.igmpublication.org/home/ ISSN (e)-2347-176x ISSN (p) 2455-0450 crossref DOI: https://dx.doi.org/10.18535/jmscr/v8i9.21

\title{
Prevalence of digestive surgical emergencies at the Amissa Bongo Regional Hospital in Franceville
}

\author{
Authors \\ Silvère OFFOBO NGAKANI ${ }^{*}$, Kadidiatou Folly DIALLO OWONO², \\ Joefred MBOGHO ABOGO ${ }^{1}$, François ONDO NDONG \\ ${ }^{1}$ Centre Hospitalier Régional Amissa Bongo de Franceville. \\ ${ }^{2}$ Centre Hospitalier et Universitaire de Libreville \\ *Corresponding Author \\ Silvère OFFOBO NGAKANI
}

\begin{abstract}
The objective of this work is to study the prevalence of digestive surgical emergencies in the surgical department of the Amissa Bongo Regional Hospital in Franceville, Gabon. This was a descriptive retrospective study of patients operated on for digestive surgical emergencies over a four-year period (September 2015 to August 2019).

During the study period, 451 digestive emergencies were operated on. The mean age was $35.32 \pm 15.24$. The most common digestive emergency was peritonitis (30.82\%). The 15-30 age group was the most affected (37.92\%). Appendicitis with a frequency of $19.73 \%(n=89)$ was the second most common emergency with a high frequency in men. Acute bowel obstruction accounted for $14.19 \%(n=64)$ of abdominal emergencies. Patients from Franceville were the most represented with $48.3 \%$, followed by those from Moanda with a frequency of 23.7\%, then from Koulamoutou (7.22\%) and Okondja (5.64\%).

Digestive surgical pathologies exist in our environment. An early diagnosis would improve care to reduce morbidity and mortality in our region.

Keywords: Prevalence, emergencies, surgical, digestive, regional hospital, Franceville Gabon.
\end{abstract}

\section{Introduction}

Emergencies in digestive surgery constitute an important part of the activities of the surgical department. A prerogative of all ages, the acute surgical abdomen has several aetiologies and still poses a problem of care, especially in Third World hospitals. In south-eastern Gabon, the Amissa Bongo hospital in Franceville regularly receives patients from the Haut Ogooué province and sometimes those from Ogooué Lolo province. The medico-surgical emergency department accommodates digestive surgical emergencies. The young, active and disadvantaged population remains the most affected in certain regions, which makes it a real public health problem ${ }^{[1,2,3]}$.

The place and issues of digestive surgical emergencies in Gabon are not well known. We have therefore taken the liberty of initiating this work, a first in our hospital environment. It extended from September 2015 to August 2019. The main objective of this work is to study the prevalence of digestive surgical emergencies in the surgical department of the Amissa Bongo Regional Hospital in Franceville. 


\section{Patients and Methods}

This was a descriptive retrospective study conducted over a period of four years (September 2015 to August 2019).

The framework of our study was the Amissa Bongo Regional Hospital of Franceville which is located in the city of Franceville, capital of the Haut-Ogooué province, itself located in the South East of the Gabonese Republic,

All patients who underwent a laparotomy for emergency digestive surgery were included. The digestive surgical emergency was defined as any emergency in visceral surgery (all ages combined), including infectious emergencies (peritonitis, acute appendicitis, anoperineal suppuration), acute intestinal obstructions, hemorrhoidal thromboses, abdominal wounds, closed abdominal trauma, Anorectal trauma and other digestive ailments requiring emergency surgery. The acute abdomens that were not operated on or died preoperatively were excluded.

Data was collected from emergency department consultation registers, patient files and operating theater report registers.

\section{Data analysis}

The following parameters were analyzed: age, sex, geographic origin and the pathologies encountered. For the data analysis, we used the software from Epi info.3.5.4. We did the usual descriptive statistics.

\section{Results}

During the study period, 1560 patients were treated in the surgical emergency department of the Amissa Bongo Regional Hospital in Franceville, among whom we identified 451 digestive surgical emergencies, which represented $28.91 \%$. The mean age was $35.32 \pm 15.24$ years (range: 4 to 95 years). The male sex was predominant $(62.52 \%)$. The age group from 15 to 30 years was the most represented with a frequency of $37.92 \%(n=171)$, followed by the group from 45 to 60 years with $22.17 \%(\mathrm{n}=100)$ and that 4 to 15 years with $16.85 \%(\mathrm{n}=76)$, however, the oldest patients were the least represented in this study with a frequency of $4.88 \%$ (Table 1).

The Amissa Bongo hospital in Franceville is a regional hub in the south-east of Gabon, in our study, patients from Franceville were the most represented with $48.3 \%$, followed by those from Moanda with a frequency of $23.7 \%$, then Koulamoutou (7.22\%) and Okondja (5.64\%). Patients from localities such as Ngouoni $(2.71 \%)$, Akiéni (2.71\%), Sucaf (3.39\%), Bongoville (1.13\%), Mounana (2.26\%), Bakoumba (0.68\%), Lastourville $(1.58 \%)$ and Mvengué $(0.68 \%)$ were the least represented in this study (Figure 1).

In our study, the most common digestive surgical emergency was peritonitis (30.82\%), which represented 139 cases. Peritonitis was the prerogative of the young subject, with a mean age of 21.52 years (range: $4-52$ years). The $15-30$ age group was the most affected (44.21\%). Appendicitis with a frequency of $19.73 \%(n=89)$ is the second most common emergency with a high frequency in men. Acute bowel obstruction (AIO) accounted for $14.19 \%(\mathrm{n}=64)$ of abdominal emergencies. The affected population was predominantly male, with a sex ratio of 4 and an average age of 30.50 years. Table 2 illustrates the different digestive surgical emergencies. Strangulated hernia was the fourth leading cause of digestive surgical emergencies with $9.75 \%$ ( $\mathrm{n}=$ 44). Closed abdominal trauma concerned 27 patients $(5.99 \%)$, mainly $85.85 \%$ male $(\mathrm{n}=$ 23/27). Hemorrhoidal thrombosis was also represented with a frequency of $5.32 \%$ or 24 patients. The other diagnoses were dominated by Fournier's gangrene (1.55\%), intussusception $(0.66 \%)$, post traumatic spleen rupture $(1.99 \%)$, abdominal wounds $(4.21 \%)$, anorectal trauma $(1.80 \%)$ and anoperineal suppurations (1.99\%). 
Table 1: Distribution of patients by age group and sex

\begin{tabular}{lccc}
\hline Age group & Female & Male & $\begin{array}{c}\text { Total workforce } \\
\text { (frequency) }\end{array}$ \\
\hline$[4-15[$ & 30 & 46 & $\begin{array}{c}76 \\
(16.85 \%) \\
171 \\
\end{array}$ \\
{$[15-30[$} & 69 & 102 & $(37.92 \%)$ \\
& & & 44 \\
{$[30-45[$} & 22 & 22 & $(9.76 \%)$ \\
& & & 100 \\
{$[45-60[$} & 30 & 70 & $38 \%)$ \\
[60-75[ & 11 & 27 & $(8.42 \%)$ \\
& & & 22 \\
{$[75-95]$} & 7 & 15 & $(4.88 \%)$ \\
Totals & 169 & 282 & $(100 \%)$ \\
\hline
\end{tabular}

Table 2: Distribution of the various abdominal surgical emergencies.

\begin{tabular}{lcc}
\hline Digestive surgical emergencies & Workforce & Frequencies (\%) \\
\hline Peritonitis & 139 & 30.82 \\
Acute appendicitis & 89 & 19.73 \\
Strangulated hernia & 44 & 9.75 \\
Acute bowel obstruction & 64 & 14.19 \\
Hemorrhoidal thrombosis & 24 & 5.32 \\
Fournier's gangrene & 7 & 1.55 \\
Intussusception & 3 & 0.66 \\
Post-traumatic spleen rupture & 9 & 1.99 \\
Abdominal wound & 19 & 4.21 \\
Closed abdominal trauma & 27 & 5.99 \\
Anorectal trauma & 6 & 1.33 \\
Anoperineal suppuration & 9 & 1.99 \\
Other & 11 & 2.43 \\
Total & 451 & 100 \\
\hline
\end{tabular}

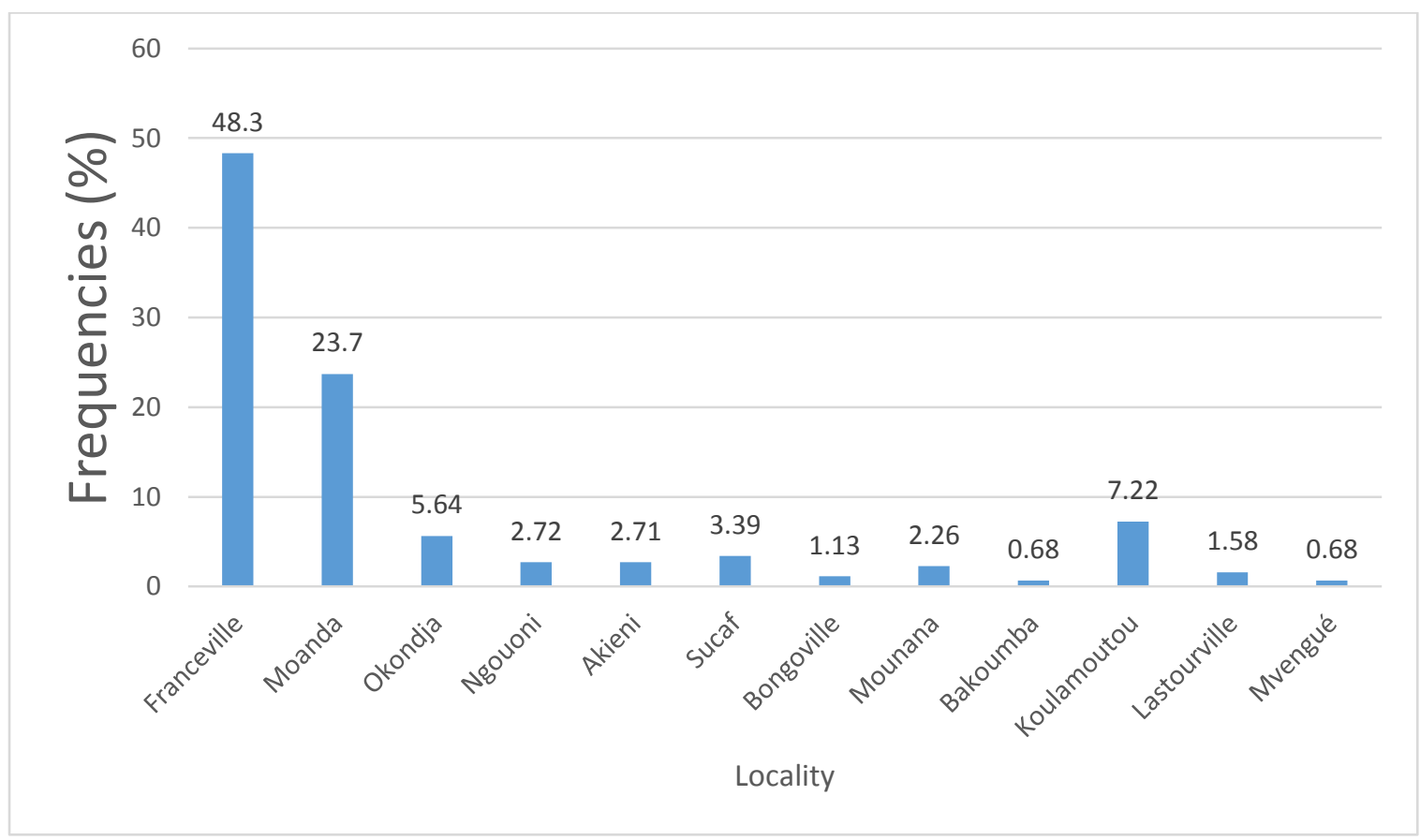

Figure 1: Distribution of patients by locality 


\section{Discussion}

Urgent digestive surgery is a frequent reason for consultation and admission. Many authors agree that the surgical acute abdomen accounts for most of the activity of the visceral surgeon in Africa ${ }^{[4,5]}$. The young population, mainly male, is a characteristic found in the African series ${ }^{[3,5]}$. This is a reflection of our demography where the age pyramid is broad based. In the West, on the contrary, where the population is aging, we find higher average ages ${ }^{[6]}$.

Appendectomy and ileostomies are the surgical procedures commonly performed in Africa and most often by laparotomy ${ }^{[5,6]}$. Vester-Andersen et al. ${ }^{[7]}$, in Denmark, in 2014, reported $53.2 \%$ of interventions on the intestinal sphere performed $93.2 \%$ by laparotomy and only $6.8 \%$ of laparoscopies, but his study had initially excluded all appendectomies. Laparotomy is still the essential first step in the surgical acute abdomen. The suspected typhoid apendicular perforation was the primary etiology of peritonitis in our patients. In our regions, typhoid fever is rife with an endemic epidemic, as in other developing countries of sub-Saharan Africa ${ }^{[8,9,10]}$. Afridi et al. ${ }^{[11]}$ in Pakistan found peptic ulcer perforation as the main etiology of peritonitis, with mean ages of 36.8 and 40.5 years respectively and male predominance. Doklestić et al. ${ }^{[12]}$ in Serbia also blamed peptic ulcer as the main source of secondary peritonitis, but the average age of its population was higher with 63.7 years and $54.41 \%$ of women. Strangled hernia, the leading cause of acute bowel obstruction, is the prerogative of young men in Africa ${ }^{[1,3]}$. South of the Sahara, patients with a priori benign surgical pathologies often only consult in the event of complications ${ }^{[5]}$. The management of a simple hernia could greatly reduce the prevalence of strangulations, sources of intestinal necrosis linked to these complications.

Simple appendicitis is one of the most frequent aetiologies in emergency digestive surgery ${ }^{[1]}$. Appendicitis in the complication stage is generally more frequent in our context due to the delay in consultation as reported by other African studies $^{[3]}$. Abdominal trauma affects young males. They are mostly caused by road accidents (AVP), assault and battery, followed by animal attacks (the majority of patients live in rural areas), and the spleen is the organ most involved ${ }^{[13]}$. The Nigerian study by Ahmed et al. in Zaria ${ }^{[8]}$ there is also a young population strongly affected by AVP, but also by the growing phenomenon of attacks by firearms. Septic complications were linked to poor operating conditions (noncompliant operating theater, peritoneal washing with running water), delayed consultation and undernutrition in our patients. In our context, peritonitis was a major contributor to parietal suppurations and septic shock as demonstrated by Riché et al. ${ }^{[14]}$ in their study establishing a direct causal link between infectious peritoneal contamination and the occurrence of septic shock. In our study, patients from Franceville were the most represented with $48.3 \%$, followed by those from Moanda with a frequency of $23.7 \%$. This work corroborates that in Dakar by Ndour et al. [15] where the greatest number of patients came from the suburbs of Dakar (65\% of cases) following the absence of pediatric surgery units in several hospitals and those originating from the interior regions of the country accounted for only $25 \%$ of cases. They explain it by a lack of appropriate means of evacuation. The lack of adequate transport for the evacuation of pathological patients from the territories of the interior of the province as well as the ignorance of these pathologies by certain practitioners in the hospitals of the interior of the province would be at the base of a weak periphery transfer rate.

\section{Conclusion}

Abdominal surgical emergencies managed in the surgical department of the Amissa Bongo Regional Hospital in Franceville are dominated by peritonitis, followed by acute appendicitis, acute bowel obstruction (AIO) and strangulated hernia. They are marked by a delay in consultation and support. 


\section{References}

1. Harissou A. Ibrahim AM. Oumarou H. et al. Retard diagnostique et implication pronostique en milieu africain : cas des urgences en chirurgie digestive à l'Hôpital national de Zinder, Niger. Eur Sci J. 2015 : $11: 251-62$

2. Mabiala-Babela JR. Pandzou N. Koutaba E. et al. Étude rétrospective des urgences chirurgicales viscérales de l'enfant au CHU de Brazzaville (Congo). Med Trop. 2006 : 66:172-6

3. Dossouvi T. Ajavon DRD. Logbo-Akey E. Dosseh ED. Urgence chirurgicales digestives et grossesse au CHU-Kara (Togo). Rev Afr chir Special. 2018: $12: 1$

4. Kambire JL Sanon BG. Zare C. Kambou T. Etiologies et pronostic des urgences chirurgicales digestives au Centre hospitalier Universitaire de BoboDioulasso (Burkina Faso). J Rech Sci Univ Lom. $2017: 19: 3$.

5. Saunders DI. Murray D. Pichel AC. et al. UK Emergency Laparotomy Network. Variations in mortality after emergency laparotomy: the first report of the UK Emergency Laparotomy Network. Br J Anaesth. 2012 : 109: 368-75

6. Saunders DI. Murray D. Pichel AC. et al. UK Emergency Laparotomy Network. Variations in mortality after emergency laparotomy: the first report of the UK Emergency Laparotomy Network. $\mathrm{Br} \mathrm{J}$ Anaesth. 2012 : 109:368-75

7. Vester-Andersen M. Lundstrøm LH. Møller MH. et al. Mortality and postoperative care pathways after emergency gastrointestinal surgery in 2,904 patients: a population-based cohort study. Br J Anaesth. 2014 : 112:860-70

8. Ahmed A. Dauda M. Garba S. Ukwenya Y. Emergency abdominal surgery in Zaria, Nigeria. S Afr J Surg. 2010 : 48:59-62
9. Hadley GP. Intra-abdominal sepsis epidemiology, aetiology and management. Semin Pediatr Surg. 2014 : 23:357-62

10. Memon AA. Siddiqui FG. Abro AH. et al. An audit of secondary peritonitis at a tertiary care university hospital of Sindh, Pakistan. World J Emerg Surg. 2012 : 7:6

11. Afridi SP. Malik F. Ur-Rahman S. et al. Spectrum of perforation peritonitis in Pakistan: 300 cases Eastern experience. World J Emerg Surg. 2008 : 3:31

12. Doklestić SK. Bajec DD. Djukić RV. et al. Secondary peritonitis - evaluation of 204 cases and literature review. J Med Life. $2014: 7: 132-8$

13. Sani R. Ngo Bissemb NM. Bade MA. et al. Les contusions de l'abdomen. Revue de 360 dossiers à l'Hôpital national de Niamey: Niger. Med Afr Noire. 2004 : 51:505-8

14. Riché FC. Dray X. Laisné MJ. et al. Factors associated with septic shock and mortality in generalized peritonitis: comparison between community-acquired and postoperative peritonitis. Crit Care. 2009 : 13:R99

15. Ndour O. Facteurs de mortalité néonatale dans le service de chirurgie pédiatrique du CHU Aristide LE Dantec de Dakar. Rev Mali Méd. 2009 : 24:33-38. 